\title{
Assessment of Friedman Classification by Measuring Actual Tonsil Size During Surgery
}

\author{
Jaeyoon Lee, MD, Soon Il Yoo, MD, Min Hyeong Lee, MD, \\ Do Hyun Kim, MD, $\mathrm{PhD}^{*}$, and Sung Won Kim, MD, $\mathrm{PhD}^{*}$ \\ Department of Otolaryngology-Head and Neck Surgery, Seoul St. Mary's Hospital, College of Medicine, \\ The Catholic University of Korea, Seoul, Korea
}

Background and Objectives: Adenotonsillar enlargement is a common cause of pediatric illnesses, including obstructive respiratory disease and recurrent airway infection. The current tonsil grading systems evaluate tonsil size, but the correlation with actual tonsillar size in a clinical setting has not been established.

Materials and Method: Between May and July of 2018, we recruited 31 children who underwent adenotonsillectomy with no major craniofacial abnormalities. The actual size of the palatine tonsils, the long (L1) and short (S1) axes of the tonsil beyond the anterior pillar, and the real axes (L2 and S2) after tonsil extraction from the fossa were measured during surgery. Adenoid size was determined by measuring the adenoid-nasopharynx (AN) ratio through lateral view x-ray of the neck.

Results: Though S1 was related to the Friedman scale $(\mathrm{p}<0.001)$, measured real axes were not $(\mathrm{L} 2: \mathrm{p}=0.058, \mathrm{~S} 2: \mathrm{p}=0.056)$. Also, adenoid size and AN ratio did not relate statistically to the Friedman scale $(p=0.565)$. One of the measured real tonsil size parameters (S2) was related to AN ratio $(\mathrm{p}=0.048)$.

Conclusion: For pediatric patients undergoing tonsillectomy and adenoidectomy, the Friedman grading scale based on physical examination may not reflect the actual size of the tonsils. Therefore, for children with obstructive sleep disorder or recurrent tonsillitis, intraoperative measurement of tonsil size can be helpful.

KEY WORDS: Tonsillectomy $\cdot$ Adenoidectomy $\cdot$ Child $\cdot$ Sleep apnea $\cdot$ Obstructive.

\section{INTRODUCTION}

Enlarged tonsils and adenoids are considered a problem in children when they cause issues such as oropharyngeal obstruction leading to mouth breathing, snoring, obstructive sleep apnea, recurrent sinusitis, hyponasal sound production, and recurrent otitis media due to blockage of the Eustachian tube. ${ }^{1)}$ Enlargement of tonsil and adenoid is related to the development of craniofacial anomalies such as adenoid face (open-mouthed face) and potential alterations in dental arches, facial bones, and muscle function with subsequent malocclusion. Enlarged tonsil and adenoid are the main cause of pediatric sleep apnea and mouth breathing. ${ }^{2)}$ Therefore, tonsillectomy and adenoidectomy are two of the most often performed childhood surgeries. ${ }^{3)}$ To calculate preoperative palatine tonsil and adenoid size, radiologic imaging, including computed tomography and magnetic resonance imaging, is available. However, these imaging

Received: September 10, 2020 / Revised: November 2, 2020 / Accepted: November 9, 2020

*These authors contributed equally to this work as corresponding author.

Address for correspondence: Sung Won Kim, MD, PhD, Department of Otolaryngology-Head and Neck Surgery, Seoul St. Mary's Hospital, College of Medicine, The Catholic University of Korea, 222 Banpo-daero, Seocho-gu, Seoul 06591, Korea

Tel: +82-2-2258-6216, Fax:+82-2-535-1354, E-mail: kswent@catholic.ac.kr

Address for correspondence: Do Hyun Kim, MD, PhD, Department of Otolaryngology-Head and Neck Surgery, Seoul St. Mary's Hospital, College of Medicine, The Catholic University of Korea, 222 Banpo-daero, Seocho-gu, Seoul 06591, Korea

Tel: +82-2-2258-6112, Fax:+82-2-535-1354, E-mail: dohyuni9292@naver.com 
examinations are not routinely conducted before surgery because of concern about excessive radiation exposure and cost-effectiveness.

Therefore, most clinicians depend on symptoms and physical examinations. The Friedman grading scale is the most commonly used method for classifying pediatric patients with tonsillar enlargement. ${ }^{4}$ This method classifies the tonsil grade by measuring the tonsil tissue beyond the anterior pillar. Therefore, the grading system may indirectly reflect actual tonsil size, and we often find that the subjective tonsil size before surgery does not match the actual palatine tonsil size measured after tonsillectomy.

In this study, we measured actual tonsil size during surgery (not the shrunken specimen after tonsillectomy) and compared it to the Friedman grading scale and adenoid size.

\section{MATERIAL AND METHODS}

The Institutional Review Board of Seoul St. Mary's Hospital (KC18TESI0723) approved this study, which was conducted in accordance with the Declaration of Helsinki. All patients gave informed consent before they were enrolled. From May to July of 2018, pediatric patients who underwent tonsillectomy and adenoidectomy at our hospital were enrolled in this study. A total of 31 children (62 tonsils) underwent tonsillectomy and adenoidectomy; none had any major craniofacial abnormalities. The patients ranged in age from 2 to 12 years (mean: $5.55 \pm 2.06$ ). There were 20 males and 11 females enrolled in this study. Each patient was subjected to tonsil grading using the Friedman grading scale after applying a Davis mouth gag during general anesthesia. Then, the long axis (L1) and short axis (S1) of the tonsil beyond the anterior pillar were measured while the Davis mouth gag was inserted (Fig. 1A). To obtain the actual, measured tonsil size, during medial traction of the tonsil, we measured the long axis (L2) and short axis (S2) from outside of the tonsil margin in the fossa (Fig. 1B). Adenoid size was determined by measuring the adenoid-nasopharynx (AN) ratio at the narrowest point through lateral view neck X-ray (Fig. 2).

All data are expressed as means \pm standard deviations. Student's t-test was used to compare the values of measured tonsils. Differences among groups were analyzed using analysis of variance (ANOVA) or Kruskal-Wallis tests. In cases of statistical significance, the ranked parameters were compared by a one-way ANOVA. A p-value less than 0.05 was considered to reflect statistical significance. All statistical analyses were performed using SAS version 9.3 (SAS Institute, Cary, NC, USA).

\section{RESULTS}

According to the Friedman grading scale, a total of 31 patients (62 tonsils) were divided into three groups. None of the patients showed grade 0 or 1 ; only grade 2,3 , or 4 were present. The measured tonsil size is presented in Table 1.
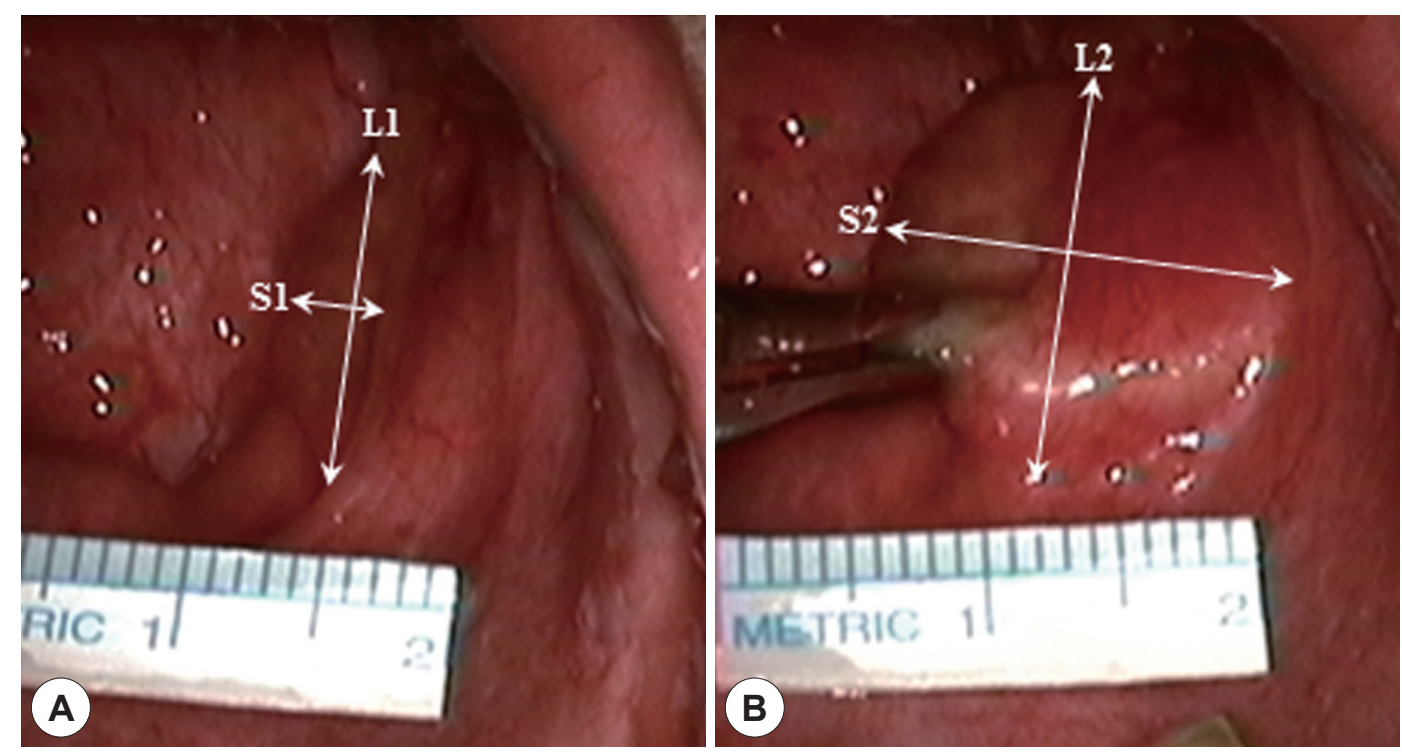

Fig. 1. The definition of palatine tonsil size. Long axis (L1) and short axis (S1) of tonsil size before traction (A) and long axis (L2) and short axis (S2) of tonsil size after traction (B). 

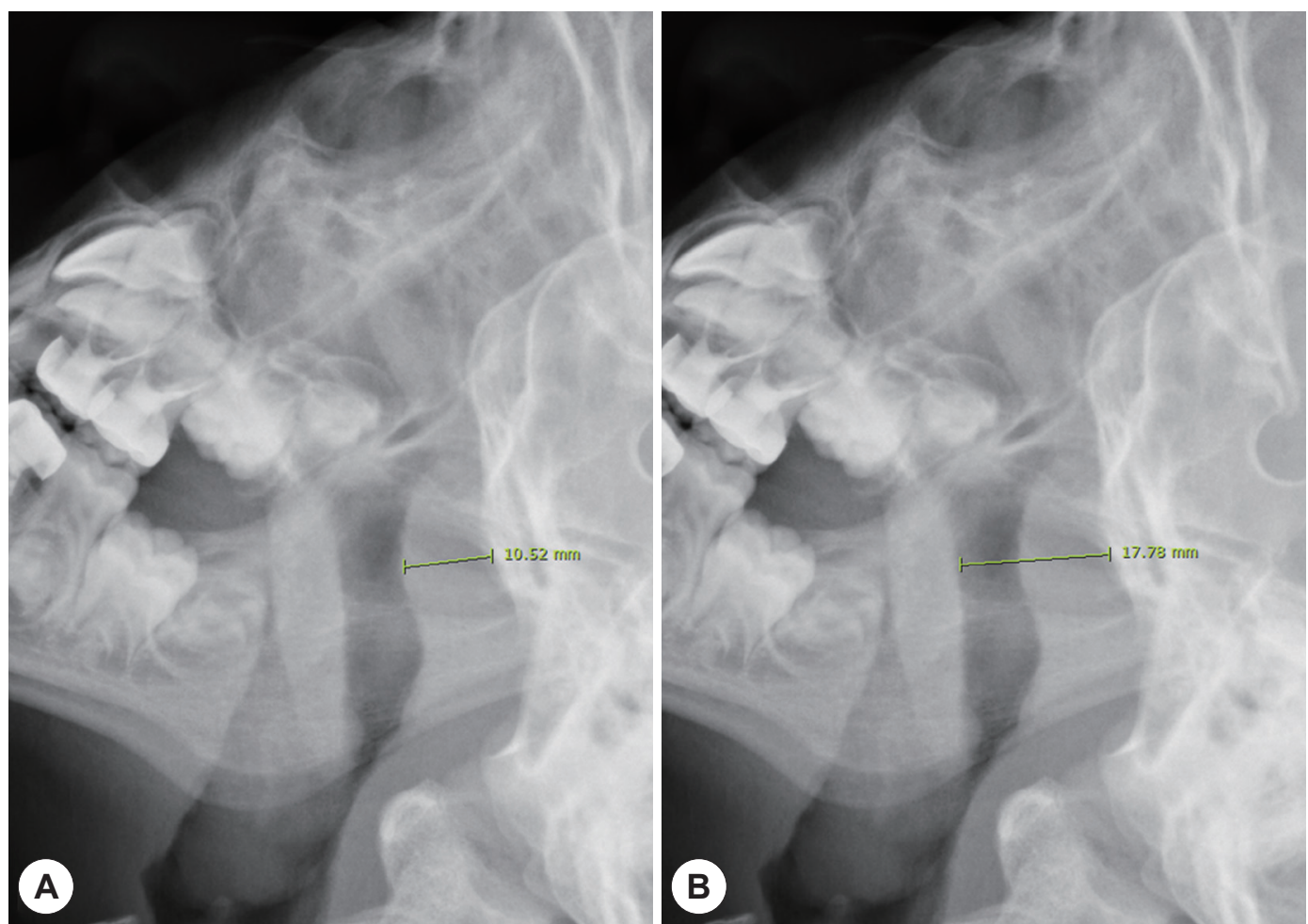

Fig. 2. Lateral neck x-ray and the adenoid-nasopharyngeal ratio. The English in this document has been checked by at least two professional editors, both native speakers of English. For a certificate, please see: http://www.textcheck.com/certificate/2VZAqH. Adenoid-nasopharyngeal ratio was determined by adenoid size (A)/diameter of nasopharynx (B) on lateral view of neck X-ray.

Table 1. Measured tonsil size

\begin{tabular}{llllllll}
\hline & \multicolumn{1}{c}{ Embedded tonsil size } & \multicolumn{2}{c}{$\mathrm{P}$-value } \\
\hline Measured tonsil size & L1 & $1.99 \pm 0.50$ & L2 & $2.31 \pm 0.48$ & L2-L1 & $0.32 \pm 0.35$ & $<0.001^{*}$ \\
& S1 & $0.90 \pm 0.36$ & S2 & $1.94 \pm 0.48$ & S2-S1 & $1.04 \pm 0.42$ & $<0.001^{*}$ \\
\hline
\end{tabular}

$*: \mathrm{p}<0.05$ for the test. L1: long axis of the tonsil beyond the anterior pillar, S1: short axis of the tonsil beyond the anterior pillar, L2: long axis of the tonsil after tonsil traction from the fossa, S2: short axis of the tonsil after tonsil traction from the fossa

The difference in the long and short axes, between the tonsil size beyond the anterior pillar and actual tonsil size, was statistically significant (long axis: $\mathrm{p}<0.001$; short axis: $\mathrm{p}<0.001)$. The short axis size showed that the embedded tonsillar portion was comparable to the tonsil size beyond the anterior pillar (S1 vs. S2-S1: $0.90 \pm 0.36$ vs. $1.04 \pm 0.42$; $\mathrm{p}=0.061$ ). Among the three grades, $\mathrm{S} 1$ increased as the grade level increased $(p<0.001$; Table 2$)$. However, the actual measured tonsil sizes (L2 and S2) did not follow the Friedman grading scale (L2: $\mathrm{p}=0.058, \mathrm{~S} 2 \mathrm{p} \mathrm{p}=0.056)$. Also, the AN ratio did not relate to the Friedman grading scale $(\mathrm{p}=0.565)$.

We also checked the correlation between the AN ratio and measured tonsil size. One of the measured real tonsil size parameters ( $\mathrm{S} 2)$ was related to the $\mathrm{AN}$ ratio $(\mathrm{p}=0.048$; Table 3).

\section{DISCUSSION}

Enlarged tonsils and adenoids in children can cause airflow limitations such as obstructive sleep apnea and various clinical conditions. ${ }^{5)}$ A child's suitability for adenotonsillectomy as a treatment for obstructive sleep apnea may be affected by physical exam results such as tonsil size. ${ }^{16-9)}$ There are three currently used grading scales, including the Friedman, Brodsky, and Three-grading scale. ${ }^{4)(10) 11)}$ All of these grading scales observe the relative position of the tonsil to the anterior pillar. Among them, the Friedman grading scale is the most commonly used method of estimating tonsil size.

Based on the results, as the Friedman grading scale increased, tonsillar short axis size beyond the anterior pillar increased. However, the Friedman grading scale did not reflect the overall actual tonsil size in this study. There have 
Table 2. Relationship between the friedman scale and measured tonsil size

\begin{tabular}{lcccc}
\hline & Grade II & Grade III & Grade IV & p-value \\
\hline Age & $5.57 \pm 1.90$ & $5.50 \pm 2.21$ & $5.75 \pm 2.06$ & 0.679 \\
L1 & $1.73 \pm 0.52$ & $2.06 \pm 0.51$ & $2.10 \pm 0.17$ & 0.080 \\
S1 & $0.53 \pm 0.14$ & $0.95 \pm 0.31$ & $1.33 \pm 0.21$ & $<0.001^{*}$ \\
L2 & $2.08 \pm 0.43$ & $2.41 \pm 0.51$ & $2.21 \pm 0.21$ & 0.058 \\
S2 & $1.69 \pm 0.29$ & $2.01 \pm 0.52$ & $1.94 \pm 0.41$ & 0.056 \\
AN ratio & $0.75 \pm 0.17$ & $0.68 \pm 0.16$ & $0.71 \pm 0.03$ & 0.565 \\
\hline
\end{tabular}

$*: \mathrm{p}<0.05$ for the test. L1: Iong axis of the tonsil beyond the anterior pillar, S1: short axis of the tonsil beyond the anterior pillar, L2: long axis of the tonsil after tonsil traction from the fossa, S2: short axis of the tonsil after tonsil traction from the fossa, AN: adenoid-nasopharynx

Table 3. Correlation between adenoid-nasopharynx ratio and measured tonsil size

\begin{tabular}{ccc} 
& \multicolumn{2}{c}{ Adenoid-nasopharynx ratio } \\
\cline { 2 - 3 } & Correlation coefficient $(\mathrm{r})$ & $\mathrm{p}$-value \\
\hline L1 & 0.076 & 0.558 \\
S1 & 0.127 & 0.324 \\
L2 & 0.136 & 0.290 \\
S2 & 0.252 & $0.048^{*}$ \\
\hline
\end{tabular}

$*: \mathrm{p}<0.05$ for the test. L1: long axis of the tonsil beyond the anterior pillar, S1: short axis of the tonsil beyond the anterior pillar, L2: long axis of the tonsil after tonsil traction from the fossa, S2: short axis of the tonsil after tonsil traction from the fossa.

been reports of the relationship between subjective tonsil size and actual palatine tonsil size. ${ }^{1213)}$ However, they measured the length of the tonsil using shrunken tonsillar specimens. Separated tissue specimens have contracted, making it difficult to assess the actual tissue size. Therefore, we tried to measure the real tonsil size in situ.

One of the important results presented in this study is that the embedded tonsil size was comparable to the tonsil size beyond the anterior pillar. In many cases, the embedded tonsil sizes were even larger than the apparent tonsil size beyond the anterior pillar. Primary clinics often prescribe simple, nasal symptom-related medicines when children have nasal stuffiness or suffer from recurrent rhinosinusitis, and as follow-up in cases where the visible tonsil sizes beyond the anterior pillar were not large enough. However, more attention should be paid to the hidden tonsils or adenoids. Insertion of a tongue depressor deep enough to cause a gag reflex to trigger pharyngeal muscle contraction might help to evaluate the embedded tonsil on physical examination.

The adenoid and palatine tonsils are components of Waldeyer's ring, which is a circular arrangement of lymphoid tissue in the pharynx. The palatine tonsils and adenoids are generally small at birth, increasing in size from the age of one to four due to an increase in immune activity. The sizes decrease throughout the years during the maturation of other lymphatic components. ${ }^{14)}$

In this respect, hypertrophy of the palatine tonsils and adenoids might follow a similar course of natural history.

Sometimes intracapsular tonsillectomy or subtotal tonsillectomy has been conducted to reduce postoperative pain. ${ }^{15) 16)}$ In many cases, the effect of remaining tonsillar tissue (i.e., embedded tonsil) was not evaluated and shortterm follow-up was conducted. Residual tonsillar tissue could regrow or serve as a reservoir for bacterial biofilms, failing to resolve adenotonsillar issues. ${ }^{17-19)}$ Therefore, additional long-term studies should be carried out with a focus on the embedded tonsil. ${ }^{20)}$

To minimize the impact of bias, a single surgeon performed the same surgical procedure for all patients. Thus, the surgical technique and operator variables that may influence the outcomes were controlled. However, a relatively small number of participants were enrolled in this study. In addition, the retrospective nature of the study renders the findings weaker than those afforded by randomized controlled studies. Further, it is necessary to develop a new grading system that can measure the palatine tonsils.

\section{CONCLUSION}

For pediatric patients undergoing tonsillectomy and adenoidectomy, Friedman grading scale based on physical examination may not reflect the actual size of the tonsils. Therefore, for children with obstructive sleep disorders or recurrent tonsillitis, intraoperative measurement of tonsil size can be helpful.

\section{REFERENCES}

1) Mitchell RB. Adenotonsillectomy for obstructive sleep apnea in children: outcome evaluated by pre- and postoperative polysomnography. Laryngoscope 2007;117(10):1844-54.

2) Bellussi LM, Marchisio P, Materia E, Passali FM. Clinical guideline on adenotonsillectomy: the Italian experience. Adv Otorhinolaryngol 2011;72:142-5.

3) Deutsch ES. Tonsillectomy and adenoidectomy. Changing indications. Pediatr Clin North Am 1996;43(6):1319-38.

4) Friedman M, Tanyeri H, La Rosa M, Lansberg R, Vaidyanathan K, Pieri S, et al. Clinical predictors of obstructive sleep apnea. Laryngoscope 1999;109(12):1901-7.

5) Dayyat E, Kheirandish-Gozal L, Sans Capdevila O, Maarafeya MM, Gonzal D. Obstructive sleep apnea in children: relative contributions of body mass index and adenotonsillar hypertrophy. Chest 2009; 136(1):137-44. 
6) Brietzke SE, Gallagher D. The effectiveness of tonsillectomy and adenoidectomy in the treatment of pediatric obstructive sleep apnea/ hypopnea syndrome: a meta-analysis. Otolaryngol Head Neck Surg 2006;134(6):979-84.

7) Marcus CL, Brooks LJ, Ward SD, Draper KA, Gonzal D, Halbower AC, et al. Diagnosis and management of childhood obstructive sleep apnea syndrome. Pediatrics 2012;130(3):e714-55.

8) Mitchell RB, Garetz S, Moore RH, Rosen CL, Marcus CL, Katz ES, et al. The use of clinical parameters to predict obstructive sleep apnea syndrome severity in children: the Childhood Adenotonsillectomy (CHAT) study randomized clinical trial. JAMA Otolaryngol Head Neck Surg 2015;141(2):130-6.

9) Nolan J, Brietzke SE. Systematic review of pediatric tonsil size and polysomnogram-measured obstructive sleep apnea severity. Otolaryngol Head Neck Surg 2011;144(6):844-50.

10) Brodsky L. Modern assessment of tonsils and adenoids. Pediatr Clin North Am 1989;36(6):1551-69.

11) Kumar DS, Valenzuela D, Kozak FK, Ludemann JP, Moxam JP, Lea $\mathrm{J}$, et al. The reliability of clinical tonsil size grading in children. JAMA Otolaryngol Head Neck Surg 2014;140(11):1034-7.

12) Wang JH, Chung YS, Jang YJ, Lee BJ. Palatine tonsil size and its correlation with subjective tonsil size in patients with sleep-disordered breathing. Otolaryngol Head Neck Surg 2009;141(6):716-21.

13) Yasan H, Aynali G, Erdogan O, Yariktas M. Does subjective tonsil- lar grading reflect the real volume of palatine tonsils? Int J Pediatr Otorhinolaryngol 2011;75(5):618-9.

14) Baugh RF, Archer SM, Mitchell RB, Rosenfeld RM, Amin R, Burns $\mathrm{JJ}$, et al. Clinical practice guideline: tonsillectomy in children. Otolaryngol Head Neck Surg 2011;144(1 Suppl):S1-30

15) Koltai PJ, Solares CA, Mascha EJ, Meng Xu MS. Intracapsular partial tonsillectomy for tonsillar hypertrophy in children. Laryngoscope 2002;112(8 Pt 2 Suppl 100):17-9.

16) Tunkel DE, Hotchkiss KS, Carson KA, Sterni LM. Efficacy of powered intracapsular tonsillectomy and adenoidectomy. Laryngoscope 2008;118(7):1295-302.

17) Bernstein JM, Reddy MS, Scannapieco FA, Faden HS, Ballow M. The microbial ecology and immunology of the adenoid: implications for otitis media. Ann N Y Acad Sci 1997;830:19-31.

18) Lindroos R. Bacteriology of the tonsil core in recurrent tonsillitis and tonsillar hyperplasia--a short review. Acta Otolaryngol Suppl 2000;543:206-8.

19) Nistico L, Kreft R, Gieseke A, Coticchia JM, Burrows A, Khampang $\mathrm{P}$, et al. Adenoid reservoir for pathogenic biofilm bacteria. J Clin Microbiol 2011;49(4):1411-20.

20) Sorin A, Bent JP, April MM, Ward RF. Complications of microdebrider-assisted powered intracapsular tonsillectomy and adenoidectomy. Laryngoscope 2004;114(2):297-300. 